\title{
Influence of the Southern Annular Mode on the sea ice-ocean system: the role of the thermal and mechanical forcing
}

\author{
W. Lefebvre and H. Goosse \\ Université Catholique de Louvain, Institut d'astronomie et de géophysique Georges Lemaître, Belgium
}

Received: 2 June 2005 - Published in Ocean Science Discussions: 27 June 2005

Revised: 15 September 2005 - Accepted: 4 November 2005 - Published: 14 November 2005

\begin{abstract}
The global sea ice-ocean model ORCA2-LIM is used to investigate the impact of the thermal and mechanical forcing associated with the Southern Annular Mode (SAM) on the Antarctic sea ice-ocean system. The model is driven by idealized forcings based on regressions between the wind stress and the air temperature at one hand and the SAM index the other hand. The wind-stress component strongly affects the overall patterns of the ocean circulation with a northward surface drift, a downwelling at about $45^{\circ} \mathrm{S}$ and an upwelling in the vicinity of the Antarctic continent when the SAM is positive. On the other hand, the thermal forcing has a negligible effect on the ocean currents. For sea ice, both the wind-stress (mechanical) and the air temperature (thermal) components have a significant impact. The mechanical part induces a decrease of the sea ice thickness close to the continent and a sharp decrease of the mean sea ice thickness in the Weddell sector. In general, the sea ice area also diminishes, with a maximum decrease in the Weddell Sea. On the contrary, the thermal part tends to increase the ice concentration in all sectors except in the Weddell Sea, where the ice area shrinks. This thermal effect is the strongest in autumn and in winter due to the larger temperature differences associated with the SAM during these seasons. The sum of the thermal and mechaninal effects gives a dipole response of sea ice to the SAM, with a decrease of the ice area in the Weddell Sea and around the Antarctic Peninsula and an increase in the Ross and Amundsen Seas during high SAM years. This is in good agreement with the observed response of the ice cover to the SAM.
\end{abstract}

\section{Introduction}

The Southern Annular Mode (SAM, also referred as the Antarctic Oscillation (AAO) or High Latitude Mode (HLM))

Correspondence to: W. Lefebvre

(lefebvre@astr.ucl.ac.be) is the dominant mode of variability of the atmospheric circulation southwards of $20^{\circ} \mathrm{S}$. It is associated with changes in the position and the strength of the westerlies (e.g. Connolley, 1997; Gong and Wang, 1999; Thompson and Wallace, 2000; Simmonds, 2003) that induce a stronger Ekman Drift towards the north in the Southern Ocean during years with high SAM index as well as an increased upwelling close to the continent and a downwelling around $45^{\circ} \mathrm{S}$ (Mo, 2000; Watterson, 2000, 2001; Cai and Watterson, 2002; Hall and Visbeck, 2002; Lefebvre et al., 2004).

The influence of the SAM on the ice cover appears more complex (Kwok and Comiso, 2002; Liu et al., 2004; Lefebvre et al., 2004) than this annular oceanic response, whose main characteristics are similar at all the longitudes. Indeed, the correlation between the SAM index and the ice extent displays a dipole, with more ice in the Ross Sea and less in the Weddell Sea. This clearly non-annular pattern appears driven by a decrease in sea level pressure in the AmundsenBellingshausen Seas when the SAM is high. This induces a deflection of the westerlies towards the south-east around the Peninsula and towards the north-east in the Ross Sector. These winds change the sea ice velocities, the advection of heat by the ocean current and advect also warmer air in the Weddell Sea and colder air in the Ross Sea, resulting in the dipole described above (Lefebvre et al., 2004). Those studies also underline that in some regions, the SAM explains only a small fraction of the internal variability of the system and a lot of other factors must be invoked in order to understand the variability of the Southern Ocean.

The SAM has a distinct effect on the location and the strength of the Antarctic Circumpolar Current (ACC), although the lack of coherence between the SAM and the circumpolar current on the multidecadal timescale shows that the circumpolar current is primarily controlled by another mode on long timescales (Hall and Visbeck, 2002). Furthermore, antropoghenic factors, could influence both the ACC and the SAM, for instance by Fyfe and Saenko (2005). 


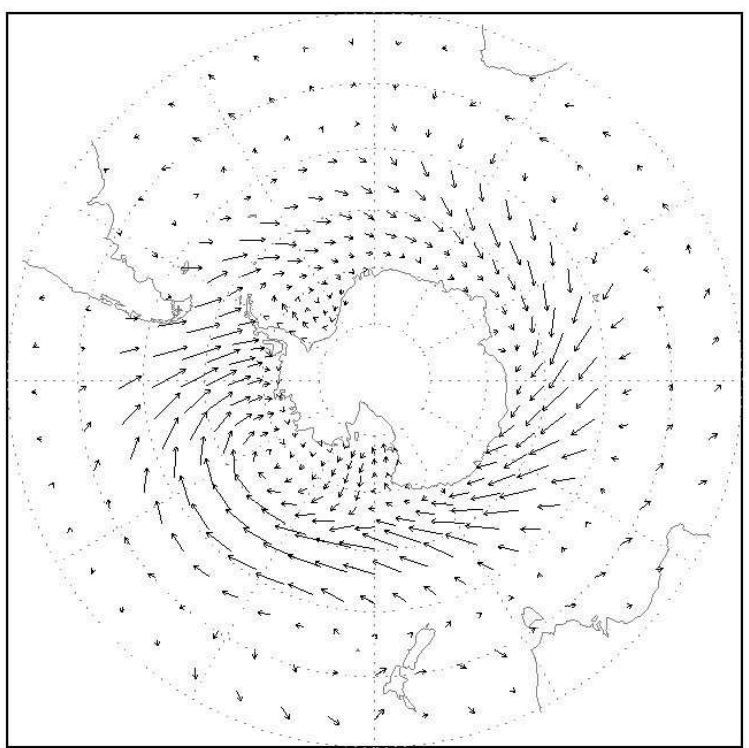

$\overrightarrow{0.07}$

Fig. 1. Annual mean of the regression between the wind stress $\left(\frac{N}{m^{2}}\right)$ and the annual mean SAM index for the period 19801999. This pattern has been used in the idealized forcings $\mathrm{M}+$, $\mathrm{S}+$ (NCEP/NCAR wind stress forcing + regression $), \mathrm{M}-$ and $\mathrm{S}-$ (NCEP/NCAR wind stress forcing - regression).

The goal of this study is to provide further information about the origin of the response of the sea ice and the ocean to the SAM. In particular, we try to disentangle the effect of the wind stress change from those resulting from the changes in air temperature. To do so, several numerical experiments have been performed with the coupled sea ice-ocean model ORCA2-LIM (Timmermann et al., 2005). In those experiments, we force the model with idealized forcings derived from the regressions between the SAM and the air temperature and the wind stress, respectively. The model and the forcings are briefly described in Section 2. Section 3 provides a justification of our methodology. In Sects. 4 and 5 , the responses to the thermal and the mechanical forcing are analyzed. Finally, the conclusions are presented.

\section{Model description and experimental design}

\subsection{Model description}

The model used here, called ORCA2-LIM, results from the coupling of the Louvain-la-Neuve sea ice model (LIM) (Fichefet and Morales Maqueda, 1997) with the hydrostatic, primitive equation ocean model OPA (Océan PArallélisé) (Madec et al., 1999). The coupling technique between OPA and LIM is identical to the one described in Goosse and Fichefet (1999). The model version used here is exactly the same as the one that has been used in Lefebvre et al. (2004), which includes a more extensive model description.

OPA is a finite difference ocean general circulation model with a free surface and a non-linear equation of state in the Jackett and McDougall (1995) formulation. The thermodynamic part of LIM uses a three-layer model (one layer for snow and two layers for ice) for sensible heat storage and vertical heat conduction within snow and ice while the sea ice velocity field is determined from a momentum balance considering sea ice as a two-dimensional continuum in dynamical interaction with atmosphere and ocean. The viscousplastic constitutive law proposed by Hibler (1979) is used for computing internal stress within the ice for different states of deformation.

The coupled model is run on a global grid with $2^{\circ}$ nominal resolution and a mesh refinement in high latitudes and near the equator. As a consequence, the meridional resolution increases to $0.5^{\circ}$ close to the Antarctic continent, corresponding to a horizontal grid width of about $50 \mathrm{~km}$. Vertical discretization uses $30 \mathrm{z}$-levels, with 10 levels in the top $100 \mathrm{~m}$. Model runs are initialized using data from the end of the 46yr experiment described by Timmermann et al. (2005). Daily 2-m air temperatures and 10-m winds from the NCEP/NCAR reanalysis project for the period 1980-1999 (Kalnay et al., 1996), and monthly climatologies of surface relative humidity (Trenberth et al., 1989), cloud fraction (Berliand and Strokina, 1980), and precipitation rate (Xie and Arkin, 1996) are utilized to drive the model. The surface fluxes of heat and moisture are determined from these data by using empirical parameterizations described by Goosse (1997).

A correction of ocean surface freshwater fluxes has been derived from the time-mean restoring salinity flux diagnosed from the experiment described by Timmermann et al. (2005) in order to circumvent the surface salinity drift that occurs through the lack of any stabilizing feedback if the model is forced with slightly incorrect evaporation, precipitation and/or river runoff fields.

\subsection{Experimental design}

In addition to the control run (CTRL) analyzed in Lefebvre et al. (2004), a series of experiments has been performed in which a perturbation of the forcing is applied on top of the normal forcing. Those idealized perturbations are derived from the regression between the SAM-index (defined as the leading principal component and the monthly NCEP reanalysis (Kalnay et al., 1996) sea level pressure anomalies south of $20^{\circ} \mathrm{S}$, which can be found at http://www.jisao.washington. edu/aao/slp/) with the wind stress and the air temperature for the period 1980-1999. In a first group of experiments (mechanical forcing), the perturbation is applied only to the wind stress: in $\mathrm{M}+$, an annual anomaly of the wind stress corresponding to one standard deviation of the SAM (regression pattern of Fig. 1) is added, while this anomaly is substracted in $\mathrm{M}-$ (Table 1). In a second group of experiments, the 
Table 1. Description of the experiments.

\begin{tabular}{lll}
\hline Name of the Simulation & Wind stress perturbation & Air temperature perturbation \\
\hline CTRL & No Change & No Change \\
M+ & +1 standard deviation & No Change \\
M- & -1 standard deviation & No Change \\
T+ & No Change & +1 standard deviation \\
T- & No Change & -1 standard deviation \\
S+ & +1 standard deviation & +1 standard deviation \\
S- & -1 standard deviation & -1 standard deviation \\
Ann+ & +1 annular part of the regression & No Change \\
Ann- & -1 annular part of the regression & No Change \\
NA+ & +1 non-annular part of the regression & No Change \\
NA- & -1 non-annular part of the regression & No Change \\
\hline
\end{tabular}

perturbation is only applied to the air temperature: in $\mathrm{T}+$, a seasonal anomaly of the air temperature corresponding to one standard deviation of the SAM (regression patterns found in Fig. 2) is added, while this anomaly is substracted in T-. In a third group of experiments, both the air temperature and the wind stress forcing have been perturbed. Adding to the standard forcing one regression between the wind stress and the air temperature and the SAM, results in S+. Subtracting them gives $\mathrm{S}-$. All these forcings have been imposed during the period 1980-1999 (see also Sect. 3). Nevertheless, as discussed in Sect. 3, we will use below only the first seven years of the simulation. This provides a robust description of the model response to the idealized forcing while avoiding some long-term effects that are not the subject of the present study.

The mechanical forcing (Fig. 1) displays an almost annular signal, with wind stress anomalies coming from the northwest. However, in the Weddell Sea and around the Antarctic Peninsula, the northern component is more intense. In Ross Sea the wind stress anomaly is in general eastwards between $50^{\circ} \mathrm{S}$ and $60^{\circ} \mathrm{S}$ and directed northwards close to the continent. Those regional features are due to the SAMrelated low-pressure area in the Amundsen-Bellingshausen Seas (Limpusavan and Hartmann, 2000). Furthermore, the increase in the magnitude of the westerlies associated with a high SAM index is slightly stronger in the Ross and Amundsen Sectors than in the Weddell and Indian Sectors.

In order to compare the impact of the annular component of the wind stress anomalies with the non-annular part, due to the low pressure in the Amundsen-Bellingshausen Seas, an additional series of experiments has been performed (Table 1). In a first group of experiments, only the zonal mean of the wind stress regression is applied (annular part of the forcing): in Ann+, the zonal mean is added to the standard forcing for the years 1980-1999, while the anomaly is substracted in Ann-. In a last series of experiments, the same methodology has been used for the non-annular anomalies
$(\mathrm{NA}+$ and $\mathrm{NA}-$ ) obtained by subtracting the zonal mean from the wind stress pattern of Fig. 1.

In all seasons, the air temperature above the Weddell Sea and around the Antarctic Peninsula is higher when the SAM is positive, while everywhere else the air temperature is lower, especially close to the continent (Fig. 2). This is in good agreement with the regression data from Thompson and Solomon (2002), who saw the same pattern in the air temperature data series on the Antarctic continent. The biggest changes are observed in autumn and winter. Although these air temperature changes appear quite large, the correlation is low (at maximum around 0.4) (Lefebvre et al., 2004). This is related to big natural variations in air temperature in this region and thus a large standard deviation of the air temperature there that leads to large regression values despite those low correlations. This implies that, even if we find a robust response of the ocean on the air temperature forcing, the low correlations of the SAM with the air temperature warns us that a lot of other factors will be at least as important for temperature changes as the SAM. As the air temperature regression pattern to the SAM is clearly non-annular, analyzing the influence of the zonal mean changes in a way similar to experiments Ann and NA for the air temperature forcing appears not very instructive and such experiments are not discussed here.

The method presented here has the advantage that we keep the interannual variability of the forcing (as we keep on having the variability in the NCEP-NCAR dataset) and that we can identify clearly the role of each component of the atmospheric forcing (wind stress or air temperature). However, this method can only be successful if the linearization provides a good approximation of the response of the real system and if there are no big, either positive or negative, feedbacks between the oceanic response on the wind stress on the one hand and the air temperature on the other hand. Furthermore, the method could pose problems because the same perturbation is applied every year. After a few years, the long term 

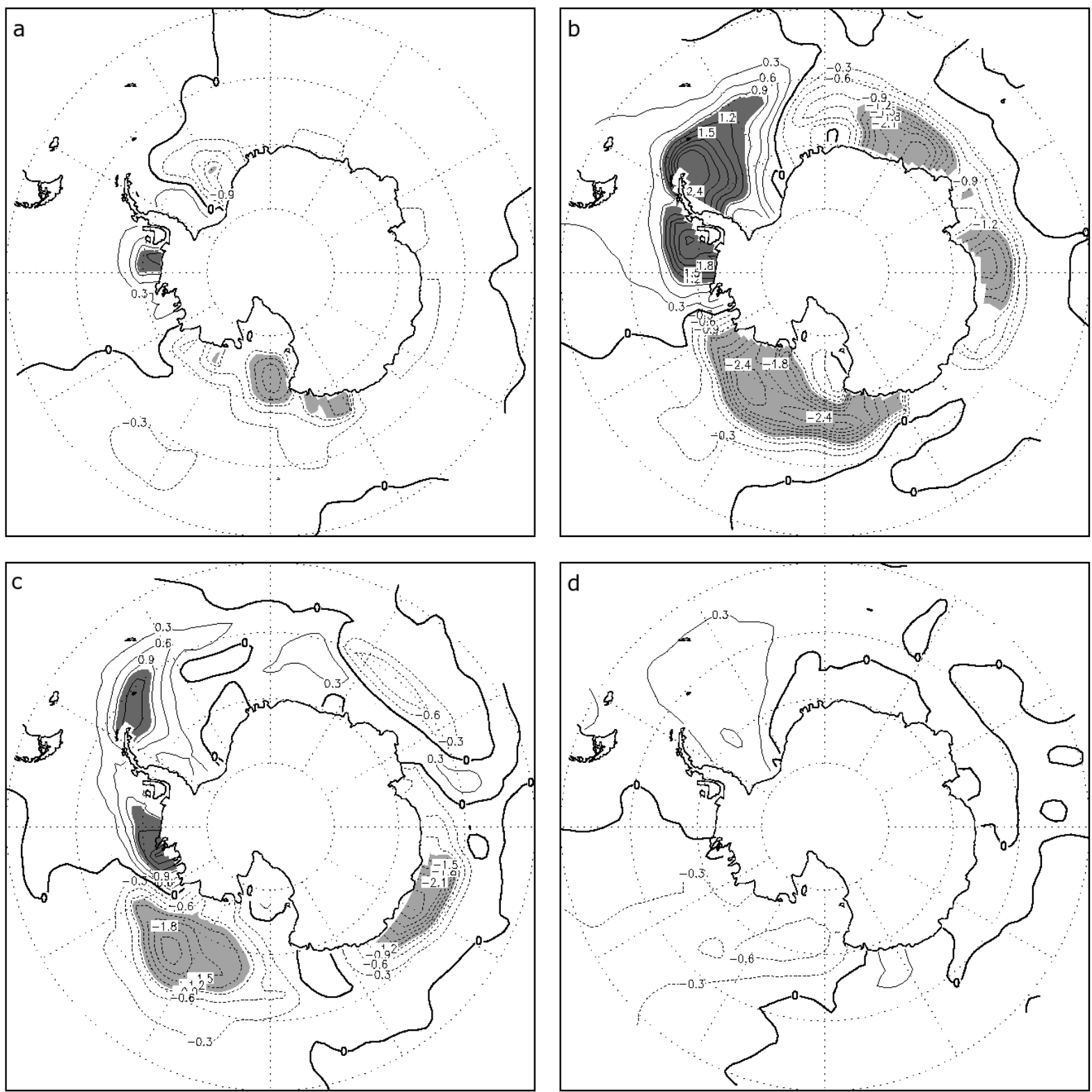

Fig. 2. Seasonal mean of the regression between the air temperature $\left({ }^{\circ} \mathrm{C}\right)($ NCEP-NCAR reanalysis (Kalnay et al., 1996)) and the seasonal mean SAM index (NCEP-NCAR reanalysis) for the period 1980-1999. (a) summer, (b) autumn, (c) winter, and (d) spring. Contour interval is $0.3^{\circ} \mathrm{C}$. Solid lines correspond to positive values, while dotted lines show negative values. Shading in dark gray means a regression of more than $1^{\circ} \mathrm{C}$, whereas shading in light gray shows a regression of less than $-1^{\circ} \mathrm{C}$. This pattern has been used in the idealized experiments $\mathrm{T}+$, $\mathrm{S}+(\mathrm{NCEP} / \mathrm{NCAR}$ air temperature forcing + regression $), \mathrm{T}-$ and $\mathrm{S}-(\mathrm{NCEP} / \mathrm{NCAR}$ air temperature forcing - regression $)$.

response of the system to a constant perturbation could thus be different than the one observed in the real world where the polarity of the SAM changes nearly each year. These limitations will be discussed in Sect. 3 .

\section{Justification of the experimental design}

3.1 Checking the linearity and comparing with the observations

The approach of this paper is only valid if the southern sea ice-ocean system responds approximately in a linear way to the SAM. This assumption could be decomposed in two parts. Firstly, it is necessary to check that the sum of the 


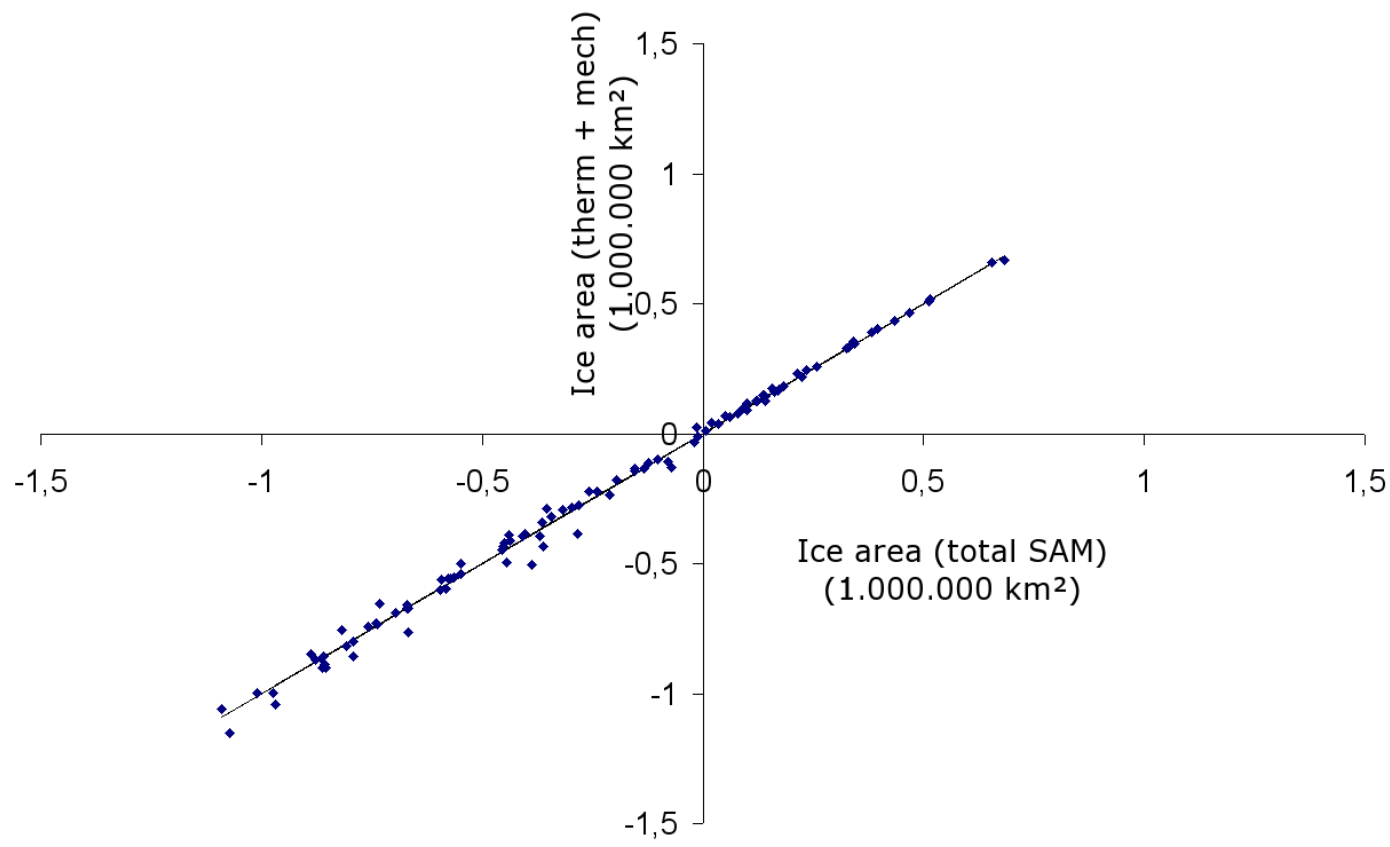

Fig. 3. For the first seven years of the simulations ( 15 points per year), we represent the following sums: on the $\mathrm{X}$-axis; the ice area (in $1000000 \mathrm{~km}^{2}$ ) of ('S+' - 'S-')/2 and on the Y-axis; the ice area (in $\left.1000000 \mathrm{~km}^{2}\right)$ of ('M+' - 'M-' + 'T+' - 'T-')/2. The line $(\mathrm{X}=\mathrm{Y})$ shows a perfect correspondence between the different sets of experiments.

response to the thermal forcing only and to the mechanical forcing only is equal to the response to the total forcing and that this response is comparable to the results of the control experiment (Lefebvre et al., 2004) and to the observations. To illustrate that, we have displayed on Fig. 3 the sum of the response of the total sea-ice area to the thermal and mechanical forcing taken separately (y-axis) as a function of the sea ice area response to the total (thermal + mechanical) forcing (x-axis). For each dot, we have selected the same time during the first seven years of the experiments in all experiments in order to have a reasonable sampling of simulated variability. As can be seen, the correlation is very good, so we can state that if we are able to understand the response to the individual forcings, we also understand the response to the total idealized forcing associated to the SAM. Furthermore, it is necessary to check if the response to this idealized forcing ( $\mathrm{S}$ ) is similar to the observed response of the ice cover to the SAM. The validity of this hypothesis is shown clearly on Fig. 4. We see that the geographical distribution of the winter sea ice response to the idealized SAM forcing in the model is very similar to the observed response in the HadISST-dataset (Rayner et al., 2003). As discussed in Lefebvre et al. (2004), this observed response is also very close to the one obtained in the control experiment. Nevertheless, there are some discrepancies that must be kept in mind when interpreting the model response, in particular, the model tends to underestimate the decrease in sea ice concentration in the Amundsen-Bellingshausen Sectors associated with a positive SAM index, while the decrease is overestimated in the Weddell Sector.
As a second aspect of the linearity issue, one has to determine if the response to an upward change in the SAM is the opposite of the response to a similar downward change in the SAM. As can be seen on Fig. 5, this is not totally valid. There is a clear linear relationship between the response to positive and negative anomalies. But, the changes induced by a decrease in the SAM are smaller than the responses due to an increase in the SAM. More precisely, on Fig. 6, we observe that the spatial distribution of the anomalies is similar in experiments $\mathrm{S}+$ and $\mathrm{S}-$ but the magnitude of the changes is larger is $\mathrm{S}+$.

3.2 Checking the dependency of the results to initial conditions and the long term effect of the SAM

The response to the SAM could be influenced by the choice of initial conditions and by the years selected to start the experiments. For example, if the SAM is already high during the first year of the experiment, does an increase of the SAM has the same effect as if the SAM was initially low? If the initial state was a cold one with a lot of sea ice, will this influence the response of the sea ice to the SAM? To answer these questions, we have started the idealized simulations at different years. In the standard experiment, the simulations are started in 1980. In addition, we have carried out experiments similar to S+ but starting in 1981, 1982 and 1983. For each of those experiments, the model is initialised using the corresponding year of the control run. The anomalies due to the modified forcings have been compared to the perturbations obtained for the experiments starting in the year 1980 . 

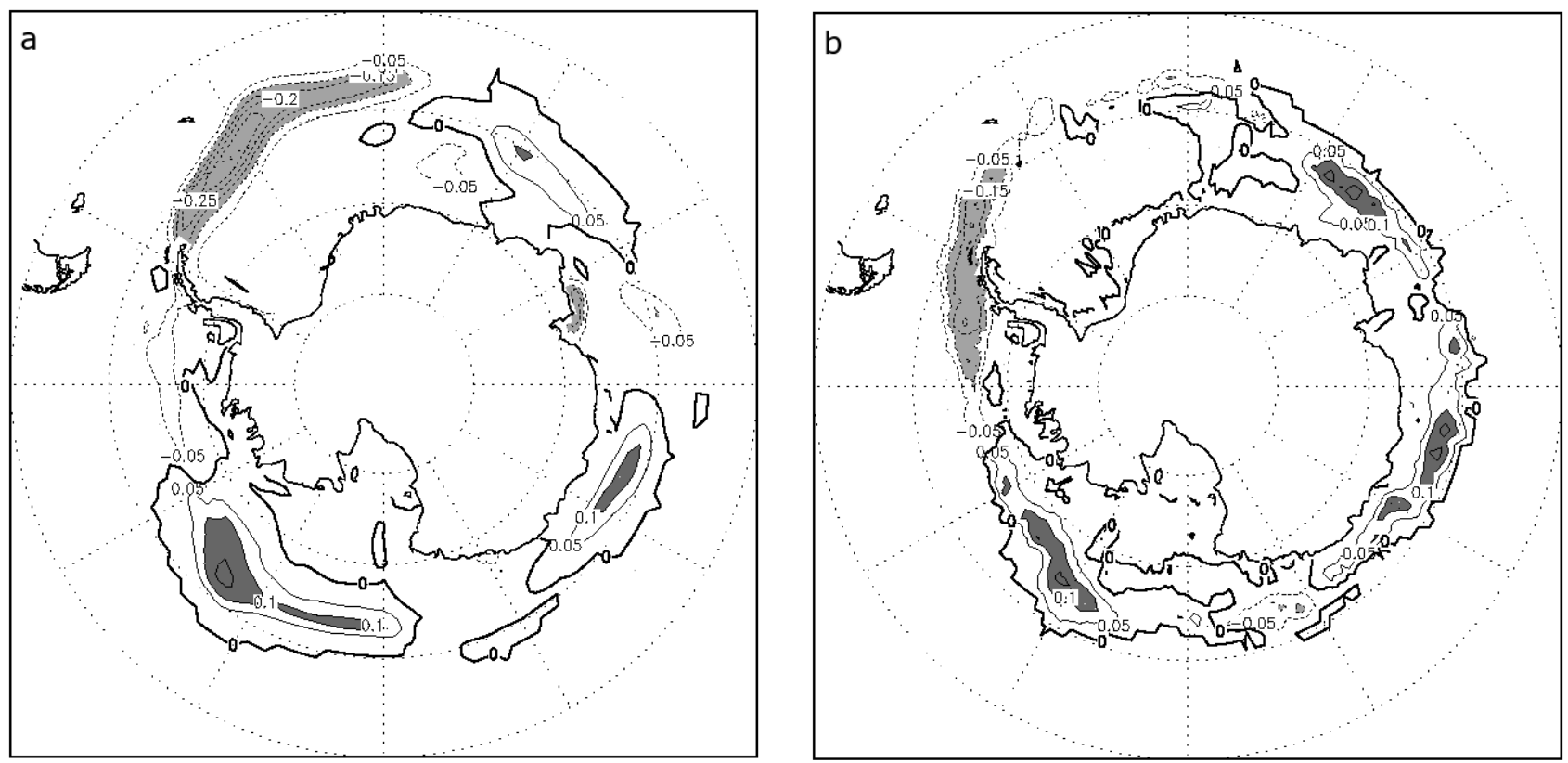

Fig. 4. (a) Half of the differences in sea ice concentration at the end of July between $\mathrm{S}+$ and $\mathrm{S}-$ for the first seven years of the idealized simulations. (b) Regression between the seasonal mean SAM index and the July mean ice concentration for the period 1980-1999 in the HadISST1 Rayner et al. (2003) observations. Contour interval is 0.05 . Solid lines are positive values, while dotted lines show negative values. Shading in dark gray means a value of more than 0.1 , whereas shading in light gray shows a value of less than 0.1 .

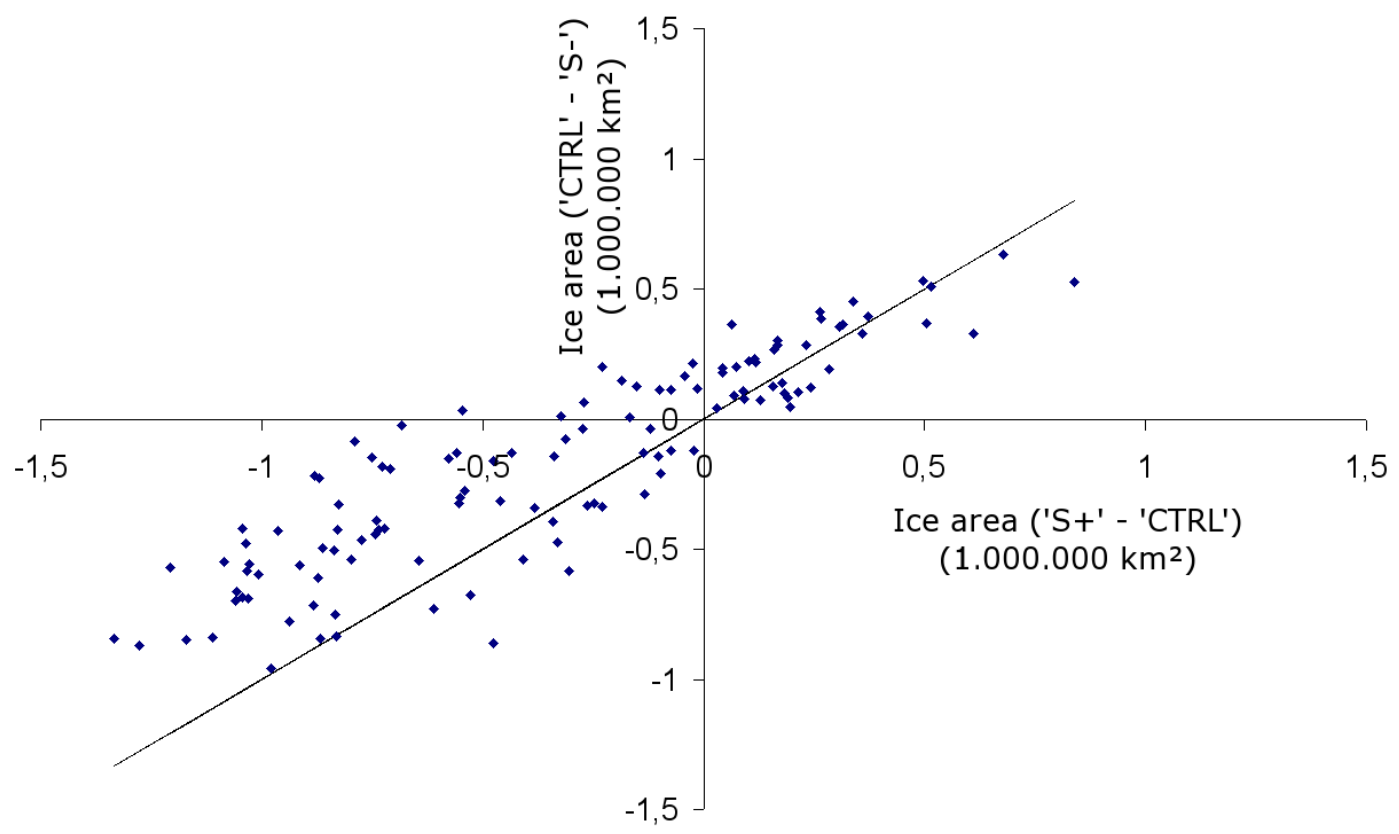

Fig. 5. For the first seven years of the simulations ( 15 points per year), we represent the following sums: on the $X$-axis; the ice area (in $1000000 \mathrm{~km}^{2}$ ) of ('S+' - 'CTRL') and on the Y-axis, the ice area (in $1000000 \mathrm{~km}^{2}$ ) of ('CTRL' - 'S-'). The line (X=Y) shows a perfect correspondence between the different sets of experiments.

We can see that the results of the various experiments (Fig. 7) are, in general, similar, although all the simulations starting in 1981, 1982 and 1983 seem to have slightly less ice the standard experiment. More precisely, they show a stronger response of the sea ice area if the sea ice area anomaly is negative and a smaller response if this anomaly is positive. If 

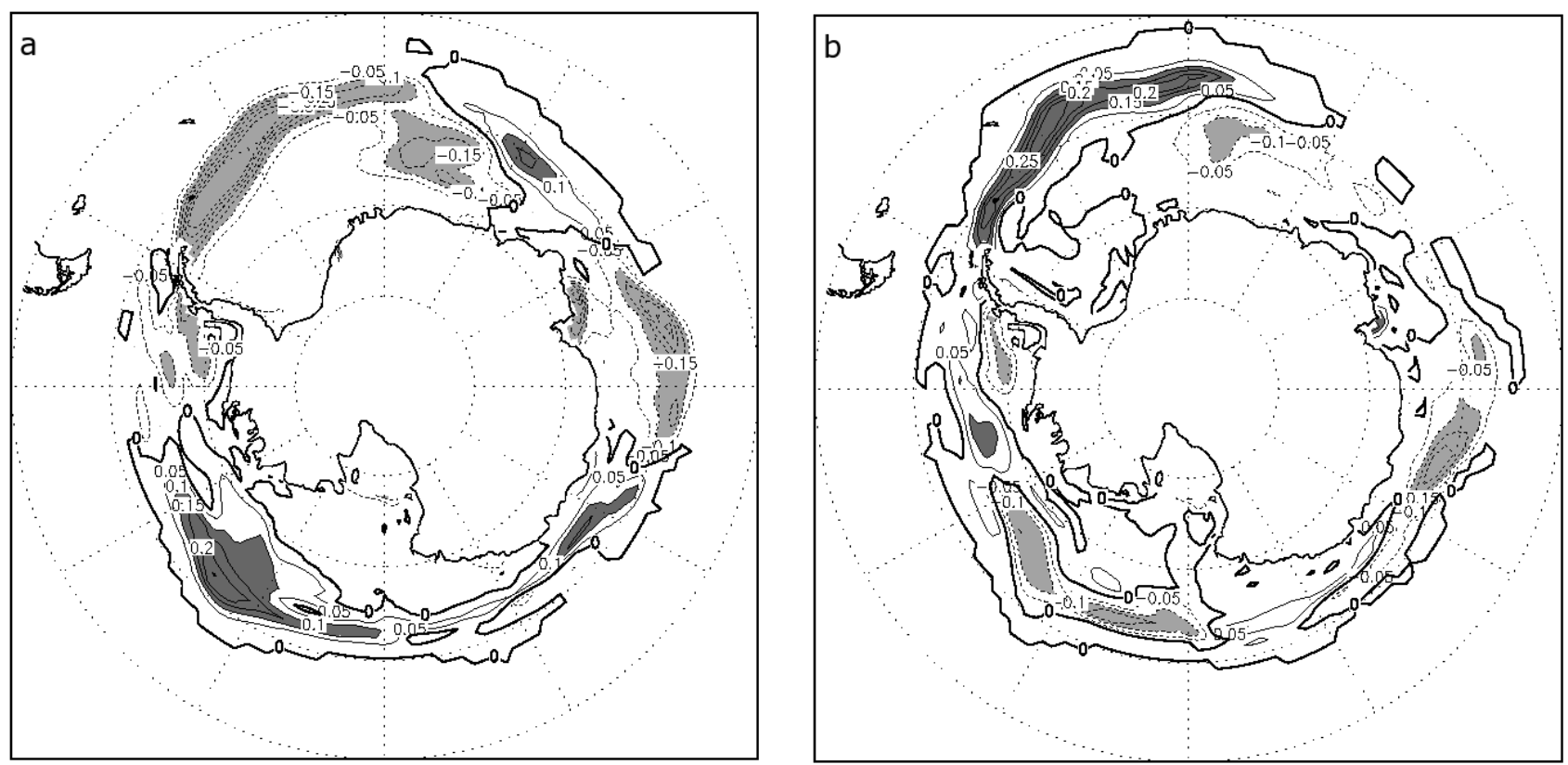

Fig. 6. (a) The difference in sea ice concentration at the end of July between S+ and CTRL for the first seven years of the idealized simulations. (b) The difference in sea ice concentration at the end of July between S- and CTRL for the first seven years of the idealized simulations. Contour interval is 0.05 . Solid lines are positive values, while dotted lines show negative values. Shading in dark gray means a value of more than 0.1 , whereas shading in light gray shows a value of less than 0.1 .

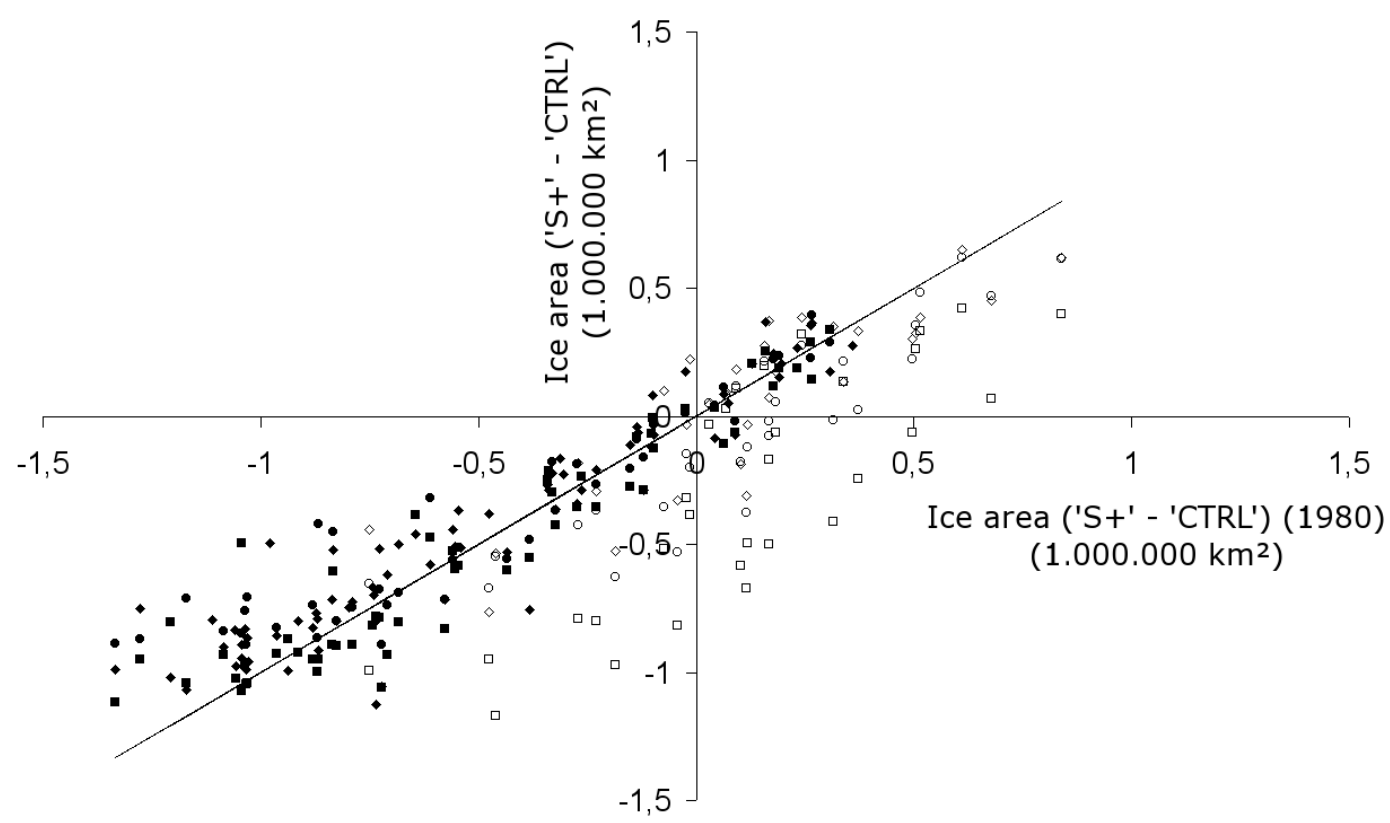

Fig. 7. The dependency of the sea ice response to the SAM to the initial conditions. Each point represents a comparison between two different initial conditions at a certain time after starting the experiment with $\mathrm{S}+$ forcing. On the $\mathrm{x}$-axis: the sea ice area anomaly (in $1000000 \mathrm{~km}^{2}$ ) (difference with the CTRL-run) after a certain time after the starting of the simulation in 1980. On the y-axis: the sea ice area anomaly (in $1000000 \mathrm{~km}^{2}$ ) (difference with the CTRL-run) after a certain amount of time after the starting of the simulation in 1981 (diamonds), in 1982 (squares) and in 1983 (circles). If the time after the beginning of the simulation is smaller than two years empty symbols are used, otherwise filled symbols are used. The line shows the perfect correspondence, i.e. the case where we get exactly the same differences whatever year we take. 


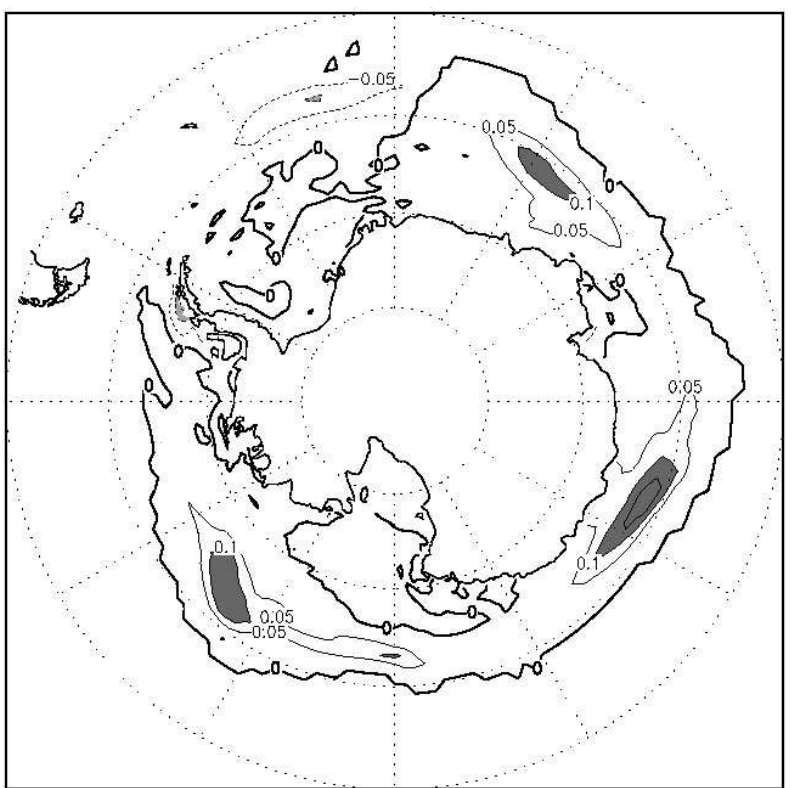

Fig. 8. Half of the differences in sea ice concentration at the end of July between $\mathrm{T}+$ and $\mathrm{T}-$ for the first seven years of the idealized simulations. Contour interval is 0.05 . Solid lines are positive values, while dotted lines show negative values. Shading in dark gray means a value of more than 0.1 , whereas shading in light gray shows a value of less than 0.1 .

we split up the results in two parts: on the one hand, the first two years after the beginning of the perturbation (empty symbols) and on the other hand, the other years (full symbols). We see that the initial conditions only play a role in the first years of the idealized simulations. Even in these years, the differences (memory effect) in the changes of the sea ice area due to the SAM, in general, account for about $200000 \mathrm{~km}^{2}$ only. This shows that the influence of initial conditions and starting years is weak. In addition, as the difference in the response of the runs starting in different years decrease with time, the observed trend in the SAM has only a negligible effect on our results. Furthermore, the natural trend of the SAM showed a sharp jump upwards at the end of the seventies. Afterwards, the index shows a sharp decline and a slight upwards trend (Marshall, 2003). In our results of the runs starting in different years, we do not see a difference that could be attributed to these natural changes in the trend of the SAM index.

Finally, we have to take into account another possible problem. We are using, in the different runs, a constant perturbation year after year. As a consequence, long term effects could kick in after a few years. The first signal of such a long term effect can be seen after eight years, when an increased convection around Maud Rise can be found in the $\mathrm{M}+$ and the $\mathrm{S}+$ experiments. To eliminate these unwanted effects, we will work in the rest of this paper with means over the first seven years of the simulation. The sea ice response to the SAM in these years, does not differ a lot from one year to another, so by averaging over these years, a reasonable SAM-like sea ice response is obtained (see above). The period 1980-1986 of the simulation provides thus a good representation of the subdecadal model response associated to the idealized perturbation. As a consequence, only results for this period are presented here. Nevertheless, analysing a period of similar length but starting at a different date would give similar conclusions.

The discussion presented in this section illustrates that the linear hypothesis used to construct our experimental design is reasonable. Our numerical experiments could thus be used to better understand the response of the ocean and sea ice as discussed hereafter.

\section{Role of the thermal forcing}

The response of the Southern Ocean to the thermal part of the SAM is relatively straightforward. The colder air in the Indian, Pacific, Ross and Amundsen sectors induces a larger sea ice cover in these regions (Figs. 2 and 8). The effect is the strongest during the seasons with the biggest changes in temperature: autumn and winter. However, in the the Weddell and Bellingshausen sectors, an increase in air temperature results only in a marginal decrease in winter sea ice concentration (see Fig. 8). The autumn ice production is lower in these regions due to the large temperature differences in this season (Fig. 2) inducing a lower ice extent (not shown). The difference in temperature decreases strongly in the winter and this induces only a small effect on the winter sea ice cover, as shown in Fig. 8. We have also to take into account the discrepancies between the observations and the model in this region, as mentioned in Sect. 3.1.

The net effect of the thermal forcing is an increase in sea ice area associated with a positive SAM index (Table 2), which reaches its maximum in June with a value of $538000 \mathrm{~km}^{2}$. The change in air temperature does not have, as could be expected, much effect on the currents. Furthermore, there are no big changes in the mixed layer depth in response to the changes in air temperature, even when taking into account the sea ice changes. However, we must recall here that the forcing used in our simulation does not include any interannual variation in precipitation and features only a reduced variability of surface heat fluxes (only temperature is varying). Taking into account this additional variability might alter the conclusion about the effect of the SAM on the density flux (e.g. Genthon et al., 2003).

\section{Role of the mechanical forcing}

In contrast to the thermal part, the mechanical forcing implies complex mechanisms. When the SAM index is high, the stronger westerlies induce enhanced zonal ocean surface currents and, due to the Ekman drift, also stronger meridional 
Table 2. Ice area winter (JAS) differences between the different simulations in $1000000 \mathrm{~km}^{2}$. T: ('T+' - 'T-')/2. M: ('M+' - 'M-')/2. Ann: ('Ann+' - 'Ann-')/2. NA: ('NA+' - 'NA-')/2. S: ('S+' - 'S-')/2. The division into sectors is as follows: Weddell Sea $\left(60^{\circ} \mathrm{W}-\right.$ $\left.20^{\circ} \mathrm{E}\right)$, Indian Ocean $\left(20^{\circ} \mathrm{E}-90^{\circ} \mathrm{E}\right)$, Pacific Ocean $\left(90^{\circ} \mathrm{E}-160^{\circ} \mathrm{E}\right)$, Ross Sea $\left(160^{\circ} \mathrm{E}-140^{\circ} \mathrm{W}\right)$ and the Amundsen-Bellingshausen Seas $\left(140^{\circ} \mathrm{W}-60^{\circ} \mathrm{W}\right)$.

\begin{tabular}{lrrrrrr}
\hline & Weddell & Indian & Pacific & Ross & $\begin{array}{r}\text { Amundsen- } \\
\text { Bellingshausen }\end{array}$ & Total \\
\hline T & -0.035 & 0.136 & 0.117 & 0.091 & 0.030 & 0.339 \\
M & -0.326 & -0.118 & -0.071 & 0.035 & -0.051 & -0.530 \\
Ann & -0.219 & -0.089 & -0.029 & -0.015 & -0.052 & -0.403 \\
NA & 0.058 & 0.098 & 0.029 & 0.078 & 0.015 & 0.279 \\
S & -0.382 & -0.020 & 0.034 & 0.110 & -0.010 & -0.269 \\
\hline
\end{tabular}

currents (Fig. 9). This is the source of a horizontal divergence close to the Antarctic continent (around $65^{\circ} \mathrm{S}$ ), which leads to oceanic upwelling there. A horizontal convergence can be found at $45^{\circ} \mathrm{S}$ and, as a consequence, a downwelling occurs there. The anomalous vertical velocities have the same sign over the whole depth of the Southern Ocean. On the other hand, the northward surface current is balanced by a southward flow around $2300 \mathrm{~m}$ depth (not shown). All these results are in fine agreement with the results of Hall and Visbeck (2002) and Oke and England (2004). In the latter paper, the oceanic response to a change in the latitude of the Southern Hemisphere Subpolar Westerly Winds was investigated, which is closely related to the SAM. In our simulations, the enhanced zonal currents give a relatively small increase in the Antarctic Circumpolar Current but its location does not change. These results are also in agreement with Hall and Visbeck (2002).

The annual mean of the zonal mean response of the mixed layer depth is displayed in Fig. 10. We can see an increase of the mixed layer depth in the Southern Ocean at almost all latitudes with a peak between $45^{\circ} \mathrm{S}$ and $60^{\circ} \mathrm{S}$. This increase is likely due to wind stirring as the region between $45^{\circ} \mathrm{S}$ and $60^{\circ} \mathrm{S}$ is also the region where the largest changes in wind stress occur. Because of the time average, Fig. 10 hides also the differences between the seasons. In particular, during the local summer, the changes are generally of the order of a few meters, but in winter they reach locally $80 \mathrm{~m}$. Although the wind stirring plays the dominant role on the zonal mean, the changes in the vertical velocity could also affect the stability of the water column locally and thus have an influence on the mixed layer depth, as discussed below.

To understand the changes in sea ice, it is necessary to look at both the annular and the non-annular components of the SAM. The non-annular component of the wind is most important in the Ross, the Bellingshausen and the Weddell sectors, with a southern wind component in Ross Sea and a northern wind component in the Weddell Sea and in the Bellingshausen sector. This yields a significant meridional component of the surface wind stress in these regions
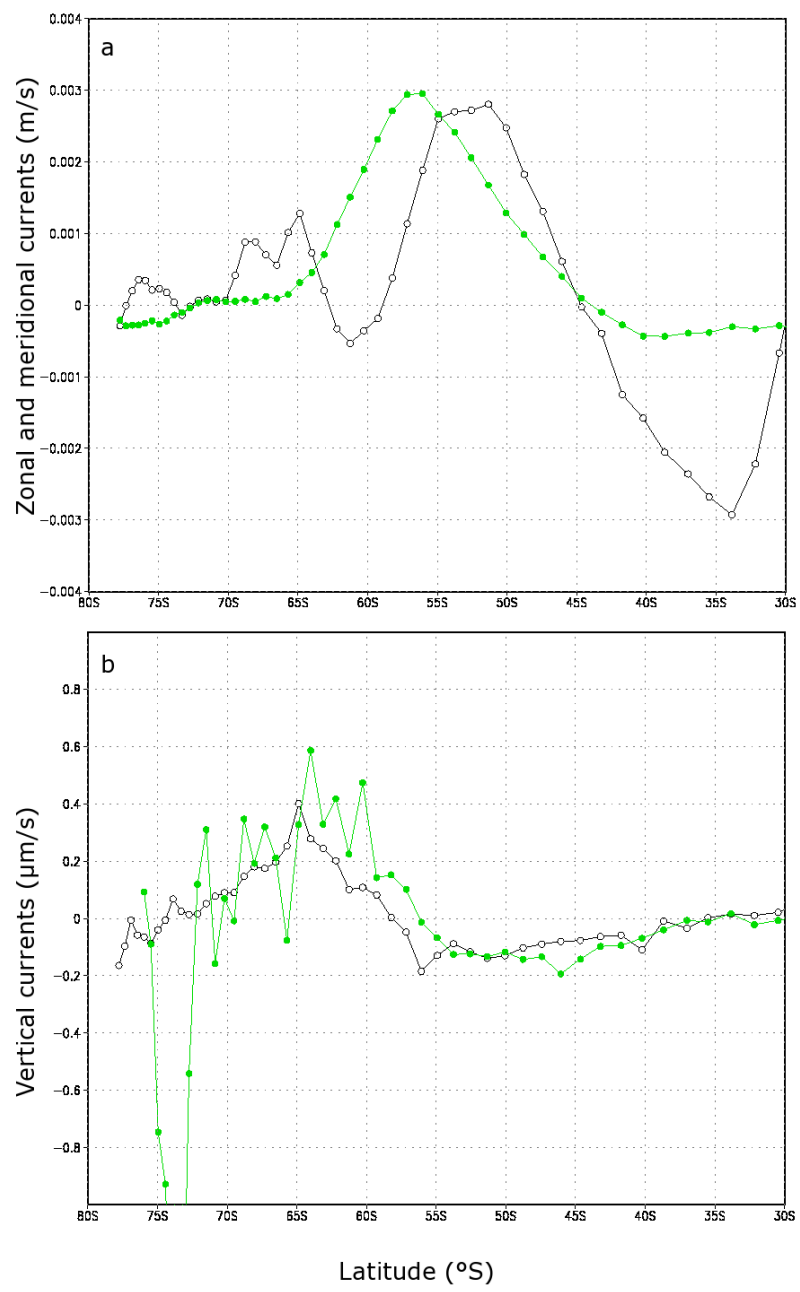

Fig. 9. Half of the annual mean differences of the zonally averaged ocean currents between $\mathrm{M}+$ and $\mathrm{M}-$ for the first seven years of the simulation. (a) the zonal surface currents (in $\frac{m}{s}$ ) (black, empty circles) and the meridional surface currents (in $\frac{m}{s}$ ) (green, full circles). (b) the vertical currents (in $\frac{\mu m}{s}$ ) at $45 \mathrm{~m}$ depth (black, empty circles) and at $2290 \mathrm{~m}$ depth (green, full circles). 


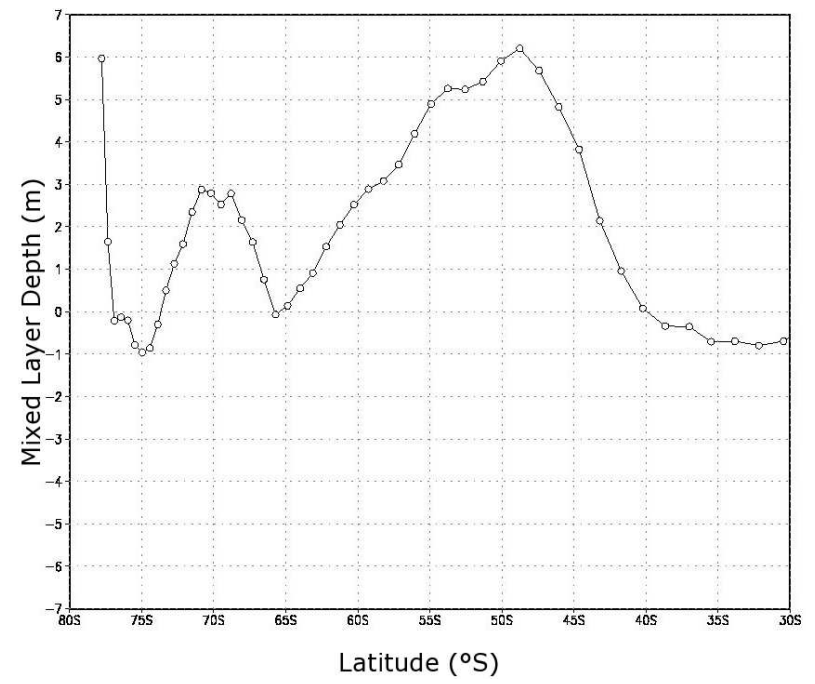

Fig. 10. Half of the annual mean differences of the zonal means of the mixed layer depth (in $\mathrm{m}$ ) between $\mathrm{M}+$ and $\mathrm{M}-$ for the first seven years of the simulation.

(Fig. 1), which is directed to the south in the Weddell and Bellingshausen Seas and towards the East-North-East in the Ross Sea. These changes in wind stress lead also to local changes in the currents.

Our sensitivity experiments (Table 1) help to determine precisely the influence of those regional anomalies compared to the annular ones. The winter annular response could be separated into two parts (Fig. 11). First of all, the annular component induces larger mixing and so induces an upward transfer of warm and salty water. Secondly, the enhanced upwelling due to the increased westerlies also pumps up warm and salty water. These two effects lead to a decrease of the sea ice concentration. In addition, this enhanced pumping of salty water could contribute to the destabilization of the water column by increasing the surface density. In this experiment, the changes in meriodional ice velocities are weak and have no significant effect on the ice cover. This contrasts with the results of Hall and Visbeck (2002), as discussed in details in Lefebvre et al. (2004). This could be due to the simple ice drift scheme in the model used by Hall and Visbeck (2002) which assumes that the sea ice velocity is the same as the oceanic velocity in the top ocean level.

The response to the non-annular wind stress forcing (Fig. 11b) shows a large change in the Ross Sea. This is due to a more northward ice drift induced by the more southerly winds. The small spots in the Bellingshausen Sea are a result of the opposite effect, i.e. a southward ice drift. The relatively small effects in the Indian and the Pacific sectors are also results of northward ice drift, induced by a slight increase in southerly wind. In the center of the Weddell Sea, the ice is pushed towards the continent. This cannot be seen clearly on the ice concentration, as the winter sea ice con- centration in the Southern Weddell Sea is close to $100 \%$, nevertheless, the sea ice thickness increases in the Southern Weddell Sea (around $70^{\circ} \mathrm{S} ; 40^{\circ} \mathrm{W}$ ). Besides, the wind stress and currents close to the Antarctic Peninsula, induce an increase in the eastward velocity of the sea ice. This leads to a sharp decrease of sea ice thickness at the eastern coast of the Peninsula.

The sum (not shown) of the responses to the annular and the non-annular wind stress forcings (Fig. 11) is close to the response to the total wind stress forcing (Fig. 12) with only some minor differences, mainly located in the Indian and Pacific Sectors. Integrated over the whole Southern Ocean, the net effect of the mechanical (wind-stress driven) part of the SAM is a decrease in ice area that reaches a September value of about $530000 \mathrm{~km}^{2}$ (Table 2).

As the winter sea ice thickness is in the Weddell Sea everywhere lower in the M+ run than in the CTRL run (due to the large response to the annular part of the forcing), the summer sea ice area decreases sharply there because the thinner sea ice melts more quickly. The total differences in sea ice area between the M+ and the CTRL runs in summer (around $577000 \mathrm{~km}^{2}$ at the beginning of March) can be accounted for the most important part to these changes in the Weddell Sea (around $499000 \mathrm{~km}^{2}$ at the beginning of March). In the Ross Sea, the differences in summer sea ice area are small (around $7000 \mathrm{~km}^{2}$ ). In the other sectors (Amundsen-Bellingshausen, Indian and Pacific), the summer ice area anomaly is small in the M+ run, as almost all the ice is melted in both runs.

\section{Conclusions}

In order to extract the role of the wind stress and the air temperature forcing in the subdecadal response associated with the SAM, we have made a series of runs with a coupled sea ice-ocean model. In those experiments, an idealized anomaly based on the regression between the NCEP-NCAR reanalysis data and the SAM index has been added to the standard forcing, some of the runs with only the mechanical part of the anomaly of the forcing, others with only the thermal part of the idealized anomaly. We have seen that the thermal part (air temperature) resulted in more sea ice when the SAM index is positive, because of the lower air temperature, mainly in autumn and winter except in the Weddell Sea and around the Peninsula where the warmer air temperature there is responsible for a decrease in the ice concentration.

The response to the mechanical forcing (wind stress) can be decomposed into several different terms. The first one is related to changes in the ice velocity, which is largely due to the non-annular part of the mechanical forcing. This is responsible for the increase in ice area in the Ross Sea as it pushes ice away of the continent. The annular part induces higher upward oceanic velocities close to the Antarctic continent due to an increased Ekman pumping when the SAM is high. As a result, warmer water rises and the ice 

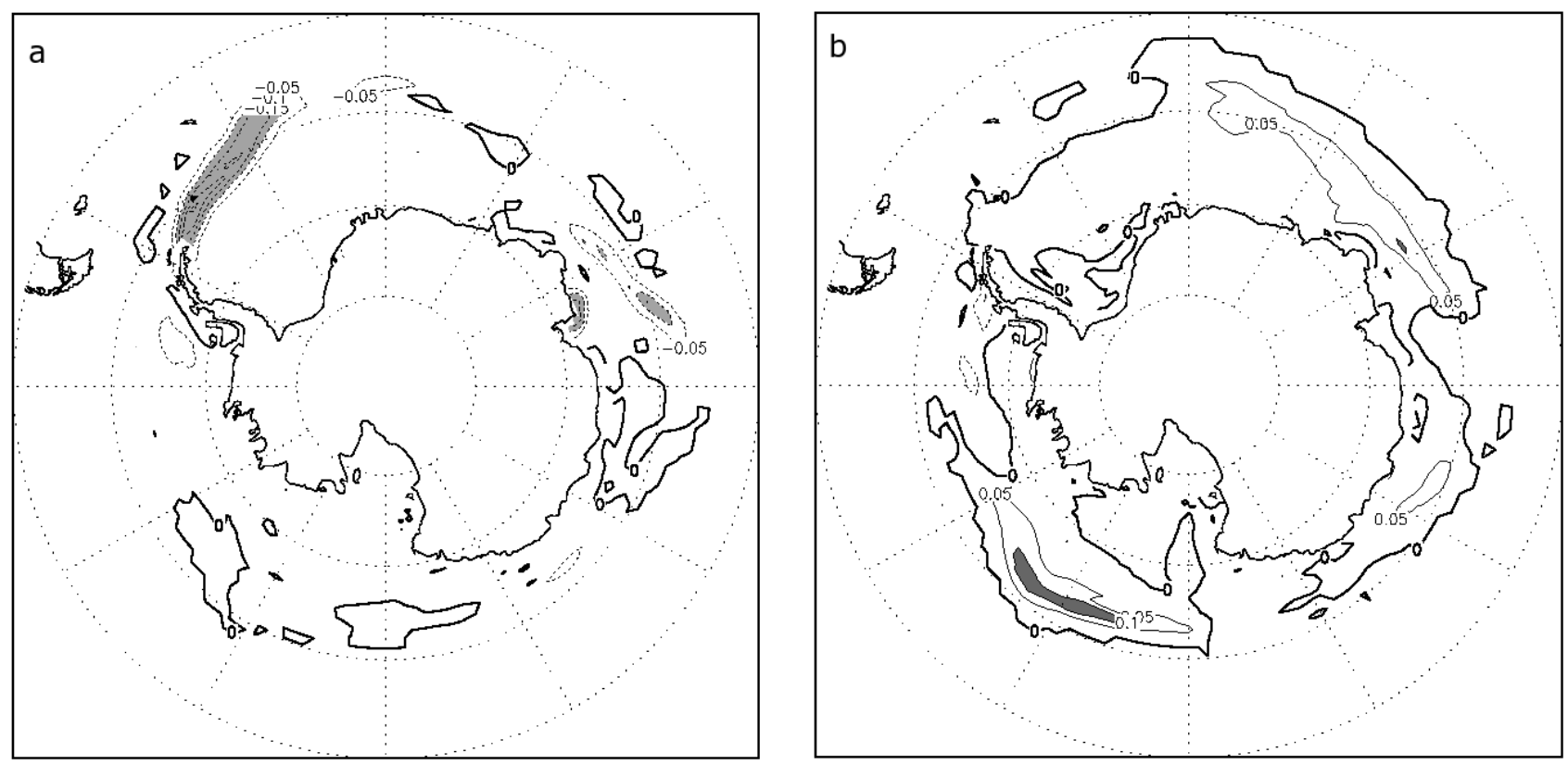

Fig. 11. (a) Half of the differences in sea ice concentration at the end of July between Ann+ and Ann- for the first seven years of the idealized simulations. (b) Half of the difference in sea ice concentration at the end of July between NA+ and NA- for the first seven years of the idealized simulations. Contour interval is 0.05 . Solid lines are positive values, while dotted lines show negative values. Shading in dark gray means a value of more than 0.1 , whereas shading in light gray shows a value of less than 0.1 .

melts. The latter effect can be seen in the Indian, the Pacific, the Ross and the Amundsen-Bellingshausen Sectors. Another effect of this pumping is the rise in surface salinity in the Weddell Sea, which destabilises the water column. This results in an increased mixing layer depth and a lesser ice area. In addition, the mechanical forcing has an effect on the currents (northward surface currents and southward deeper in the ocean, pumping close to the continent, downwelling around $40^{\circ} \mathrm{S}$ ) and on the mixed layer depth (increased mixed layer depth due to increased wind stirring and locally to the increased upwelling) and the salinity.

When analysing the ocean currents, the results of the total forcing are, in general, very close to those from the runs with only wind-stress forcing. This is logical, as it is the wind stress and not the air temperature that forces the Ekman Drift.

For the ice cover, the response to the SAM forcing can be explained as the sum of the responses to the distinct mechanical and thermal forcing. The combination of the two gives a dipole in winter, with less ice in the Weddell Sector and more ice in the Ross Sector (Fig. 4). The response in the Eastern Bellingshausen Sector follows the Weddell Sector, whereas the Western Amundsen Sector has a behaviour similar to the Ross Sector. In the other sectors, the decreases in sea ice concentration due to the enhanced pumping in the winter sea ice concentration are compensated by the increases due to the lower air temperatures. These changes are all in good agreement with the observations and with our previous experiments (Lefebvre et al., 2004) (Fig. 4). When integrated

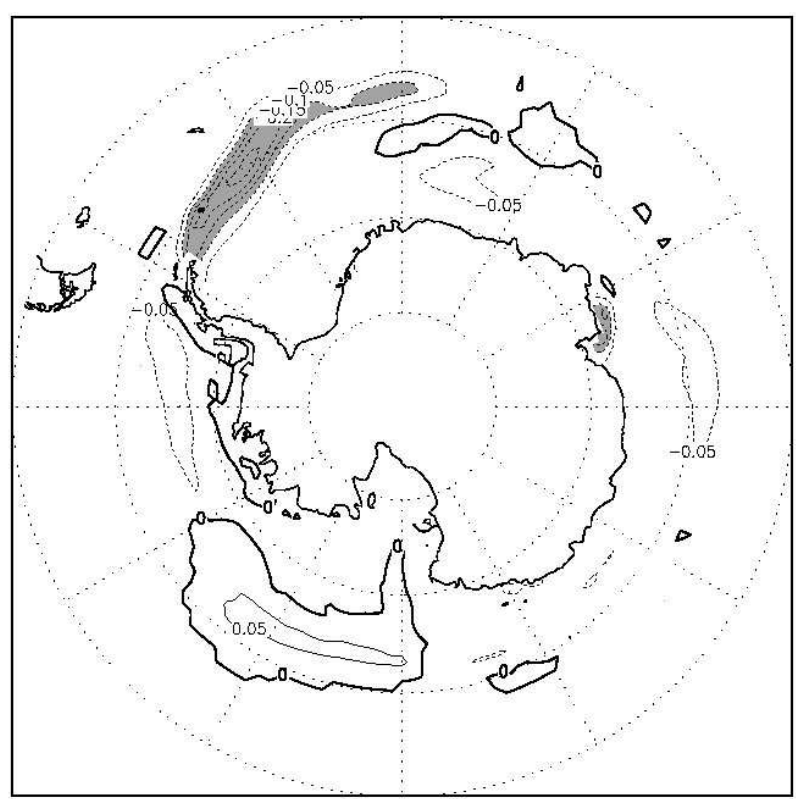

Fig. 12. Half of the differences in sea ice concentration at the end of July between $\mathrm{M}+$ and $\mathrm{M}-$ for the first seven years of the idealized simulations. Contour interval is 0.05 . Solid lines are positive values, while dotted lines show negative values. Shading in dark gray means a value of more than 0.1 , whereas shading in light gray shows a value of less than 0.1 . 
over the different sectors (Table 2), we see that the decrease in ice extent in the Weddell Sea and the increase in the Ross Sea is noticed in nearly all the runs. For those two areas, the thermal and mechanical effects tend thus to reinforce each other. On the other hand, mechanical and thermal forcing tend to have opposite responses in the other sectors, resulting in weaker total changes. The responses to the thermal and mechanical forcing have more or less the same amplitude. This shows that, despite the low correlation between the SAM index and the air temperature, the thermal forcing could by all means not be neglected. This is due on the one hand to the large variability of the air temperature in the polar areas (low correlations are thus not associated with small temperature changes) and on the other hand to the strong impact of temperature changes on the ice cover.

Table 2 also illustrates that, integrated over the whole Southern Ocean, the thermal forcing induces an increase in the ice extent, while the mechanical forcing is responsible for a decrease of the ice extent. The latter is mainly due to the annular part of the forcing since the non-annular part is associated with an increase of the ice extent. Overall, the SAM is associated with an decrease of the ice extent in winter in our simulations. Nevertheless, the complexity of the geographical distribution of the response and of the mechanisms involved with compensating effect of thermal and mechanical forcing imply that any long term influence of the SAM on the ice extent integrated over the Southern Hemisphere is very difficult to estimate from the available information. As a consequence, this integrated response could not be considered as a robust model result at this stage.

Furthermore, we must keep in mind that our distinction between the thermal and the mechanical forcing is a bit artificial. First, in the real world, changes in wind direction (and thus in wind stress) are generally associated with changes in air temperature. In this case, both wind stress and temperature changes could be related to a common cause. Secondly, our experimental design does not allow to take into account any feedback between the atmosphere and the ice-ocean system. For instance, a change in the wind stress could induce a modification of the location of the ice edge and thus a change in air temperature that could amplify the initial response. By using our experimental design, those changes in wind stress and air temperature would appear unrelated while in this example they are strongly linked. As a consequence, our experiments show clearly that both changes in mechanical and thermal forcing are important to understand the response of the ice-ocean system but we are not able in the present framework to determine the links between those two forcing or to analyse the way the atmospheric anomalies are produced.

Acknowledgements. This study is supported by the Federal Science Policy Office (Belgium) (contracts EV/10/7D and EV/10/9A) and the Action Concertée Incitative Changement Climatique (Project Changement Climatique et Cryosphère) from the French Ministry of Research. H. Goosse is Research Associate with the Belgian National Fund for Scientific Research. The NCEP-NCAR reanalysis data were provided through the NOAA-CIRES Climate Diagnostics Center, Boulder.

Edited by: D. Stevens

\section{References}

Berliand, M. E. and Strokina, T. G.: Global distribution of the total amount of clouds (in Russian), 71 pp., Hydrometeorological, Leningrad, Russia, 1980.

Cai, W. and Watterson, I. G.: Modes of Interannual Variability of the Southern Hemisphere Circulation Simulated by the CSIRO Climate Model, J. Clim., 15, 1159-1174, 2002.

Connolley, W. M.: Variability in annual mean circulation in southern high latitudes, Clim. Dyn., 13, 745-756, 1997.

Fichefet, T. and Morales Maqueda, M. A.: Sensitivity of a global sea ice model to the treatment of ice thermodynamics and dynamics, J. Geophys. Res., 102(C6), 12 609-12 646, 1997.

Fyfe, J. C. and Saenko, O. A.: Human-Induced Change in the Antarctic Circumpolar Current, J. Clim., 18, 3068-3073, 2005.

Genthon, C., Krinner, G., and Sacchettini, M.: Interannual Antarctic tropospheric circulation and precipitation variability, Clim. Dyn., 21, 289-307, doi:10.1007/s00382-003-0329-1, 2003.

Gong, D. and Wang, S.: Definition of Antarctic oscillation index, Geophys. Res. Lett., 26(4), 459-462, 1999.

Goosse, H.: Modelling the large-scale behaviour of the coupled ocean-sea-ice system, PhD thesis, 231 pp., Fac. des Sci. Appl., Univ. Cath. de Louvain, Louvain-la-Neuve, Belgium, 1997.

Goosse, H. and Fichefet, T.: Importance of ice-ocean interactions for the global ocean circulation: A model study, J. Geophys. Res., 104, 23 337-23 355, 1999.

Hall, A. and Visbeck, M.: Synchronous Variability in the Southern Hemisphere Atmosphere, Sea Ice, and Ocean Resulting from the Annular Mode, J. Clim., 15, 3043-3057, 2002.

Hibler III, W. D.: A dynamic thermodynamic sea ice model, J. Phys. Oceano., 9(4), 815-846, 1979.

Jackett, D. R. and McDougall, T. J.: Stabilization of hydographic data, J. Atmos. Ocean. Tech., 12, 381-389, 1995.

Kalnay, E., Kanamitsu, M., Kistler, R., Collins, W., Deaven, D., Gandin, L., Iredell, M., Saha, S., White, G., Woollen, J., Zhu, Y., Chelliah, M., Ebisuzaki, W., Higgins, W., Janowiak, J., Mo, K. C., Ropelewski, C., Wang, J., Leetmaa, A., Reynolds, R., Jenne, R., and Joseph, D.: The NCEP/NCAR 40-year reanalysis project, Bull. Am. Meteorol. Soc., 77, 437-470, 1996.

Kwok, R. and Comiso, J. C.: Spatial patterns of variability in Antarctic surface temperature: Connections to the Southern Annular Mode and the Southern Oscillation, Geophys. Res. Lett., 29(14), 1705, doi:10.1029/2002GL015415, 2002.

Lefebvre, W., Goosse, H., Timmermann, R., and Fichefet, T.: Influence of the Southern Annular Mode on the sea ice-ocean system, J. Geophys. Res., 109, C09005, doi:10.1029/2004JC002403, 2004.

Limpasuvan, V. and Hartmann, D. L.: Wave-maintained annular modes of climate variability, J. Clim., 13, 4414-4429, 2000.

Liu, J., Curry, J. A., and Martinson, D. G.: Interpretation of recent Antarctic sea ice variability, Geophys. Res. Lett., 31, L02205, doi:10.1029/2003GL018732, 2004.

Madec, G., Delecluse, P., Imbard, M., and Lévy, C.: OPA 8.1 Ocean General Circulation Model reference manual, Notes du Pôle de 
modélisation, Institut Pierre-Simon Laplace (IPSL), France, X, 91 pp., 1999.

Marshall, G. J.: Trends in the Southern Annular Mode from Observations and Reanalyses, J. Clim., 16, 4134-4143, 2003.

Mo, K. C.: Relationships between Low-Frequency Variance in the Southern Hemisphere and Sea Surface Temperature Anomalies, J. Clim., 13, 3599-3610, 2000.

Oke, P. R. and England, M. H.: Oceanic Response to Changes in the Latitude of the Southern Hemisphere Subpolar Westerly Winds, J. Clim., 17, 1040-1054, 2004.

Rayner, N. A., Parker, D. E., Horton, E. B., Folland, C. K., Alexander, L. V., Rowell, D. P., Kent, E. C., and Kaplan, A.: Global analyses of sea surface temperature, sea ice, and night marine air temperature since the late nineteenth century, J. Geophys. Res., 108(D14), 4407, doi:10.1029/2002JD002670, 2003.

Simmonds, I.: Modes of atmospheric variability over the Southern Ocean, J. Geophys. Res., 108(C4), 8078, doi:10.1029/2000JC000542, 2003.

Thompson, D. W. J. and Solomon, S.: Interpretation of Recent Southern Hemisphere Climate Change, Science, 296, 895-899, 2002.
Thompson, D. W. J. and Wallace, J. M.: Annular modes in the Extratropical Circulation. Part I: Month-to-Month Variability, J. Clim., 13, 1000-1016, 2000.

Timmermann, R., Goosse, H., Madec, G., Fichefet, T., Ethe, C., and Dulière, V.: On the representation of high latitude processes in the ORCALIM global coupled sea ice-ocean model, Ocean Modelling, 8(1-2), 175-201, doi:10.1016/j.ocemod.2003.12.009, 2005.

Trenberth, K. E., Olson, J. G., and Large, W. G.: A global ocean wind stress climatology based on the ECMWF analyses, National Center for Atmospheric Research, NCAR/TN-338+STR, 93 pp., NCAR, Boulder, USA, 1989.

Watterson, I. G.: Southern midlatitude zonal wind vacillation and its interaction with the ocean in GCM simulations, J. Clim., 13, 562-5783, 2000.

Watterson, I. G.: Zonal wind vacillation and its interaction with the ocean: Implication for interannual variability and predictability, J. Geophys. Res., 106, 23 965-23 975, 2001.

Xie, P. and Arkin, P. A.: Analyses of global monthly precipitation using gauge observations, satellite estimates and numerical model predictions, J. Clim., 9, 840-858, 1996. 